\title{
The Training Strategy of Image Thinking in Choreographer
}

\author{
Lixiong Gao \\ Weinan Normal University, Weinan, Shaanxi, 714099
}

Keywords: choreographer; image thinking; dance teaching

\begin{abstract}
Dance is an ancient form of artistic performance with rich connotations and diverse forms. With the continuous development of social civilization, people's aesthetic consciousness is also constantly improving, and spiritual needs and aesthetic ability have undergone a great deal changes more than before. The corresponding demand for artistic performance is also growing. As an important form of artistic performance, dance must continue to innovate and advance with the times in order to better meet people's needs for spiritual civilization. Therefore, the requirements for the overall quality of choreographers are getting higher and higher. In dance performances, choreographers must have a strong comprehensive ability to present abstract sensuous concepts through dance performances in order to achieve sympathy with the audience in the spirit level, and ultimately to create dance works with strong artistic charm. This paper mainly discusses the training of image thinking in choreography.
\end{abstract}

\section{Introduction}

An excellent choreographer must have at least the following qualities:

The choreographer must use his or her own senses to perceive various things and emotions in life, and then consciously enrich and beautify the objective things through emotional processing, and finally form image memory. The choreographer must repeatedly perceive a large number of appearances in order to further sublimate his subjective consciousness and emotions, and then finally turn into images, accumulating more suede for the follow-up dance creation. Everywhere in life is beautiful. Choreographers must possess a pair of eyes that discover beauty. With careful observation and keen perception, they can profoundly perceive the life images and touching emotions contained in life, and thus inspire dance creation inspiration. For example, Liping's masterpiece "The Spirit of the Witch" is a complete and omni-directional observation of the peacock. This shows that the keen perception can enrich the choreographer's experience and help him to accumulate more experience.

There is a direct correlation between the depth of thought and aesthetics of a dance work and the comprehension ability, speculative ability and aesthetic ability of choreographers. If the choreographer lacks strong comprehension ability and speculative abilities, his understanding and recognition of human nature and life is also important. Relatively simple, it is impossible to deeply grasp the character's role, psychological, and personality traits. A good choreographer must keep pace with the times, recognize the essence of his current life, and form his own unique understanding and understanding of new social phenomena and new artistic trends, better build a dance structure, enrich dance content, and improve The depth of dance works. For instance, Wang Mei's modern dance drama "Lei Yu Yu" can be seen to contain the sincere humanistic care and the author's deep understanding of life. These are the results of positive thinking of the director of social life.

The rich imagination is the most important ability in the cultivation of the images of dance directors. The creation of dance works is not only the experience and experience of the director, but also the emotion and imagination of the author, and finally the new image formed through the dance movement. come out. For example, in Chen Wei's "Qin Chuang Soul”, after the terracotta warriors and horsemen were visited, the author imagined and thought about the memory appearance formed, and then incorporated his own emotions. Finally, the entire work expressed the imposing manner of the Qin Dynasty's military. In addition, although the choreographer's personal life experience has 
direct relevance, the author cannot experience all the things and types in life. This part of experience and cognition needs to be obtained through other means. Therefore, choreographers must continue to learn about culture and Art knowledge, accumulated rich cultural heritage, enriched art knowledge, enriched the means of choreography, and expanded the artistic vision.

\section{The Importance of Image Thinking in Choreographer}

Image thinking is a way of thinking that transforms abstract emotions into figurative things. It takes the perceptual image as a starting point and presents the essence of life and society. Dance is a spiritual level activity. Active image thinking is a necessary condition for transforming the objective things perceived by creators into common concepts. The establishment of stage images has a direct relationship with the development of image thinking. The dance performance process includes a series of gestures and body movements. The choreographer must continue to expand the imagination space through image thinking, giving the dance works a more profound connotation and higher aesthetic significance. Specifically, the cultivation of students' image thinking in dance choreography teaching has several important meanings:

The so-called divergent thinking means that the thinking subject may carry out in-depth thinking and research based on different angles and levels. Divergent thinking reflects the characteristics of flexibility, fluency, and uniqueness. The thinking subject may produce a lot of results within a certain period of time. Ideas and ideas, divergent thinking is also one of the important forms of image thinking. In the process of teaching choreographers, teachers should consciously guide students to analyze problems based on different perspectives, and allow students more time to think about them, so as to lay a solid foundation for students' image thinking.

The process of creating a brand-new image in the mind through independent exploration and thinking based on a specific goal and task is imagination. Imagination is a complicated psychological process. Imagination subjects produce consciousness in the process of implementing objective practice. This perception will leave an appearance in the brain, and then beautified and processed in combination with the actual situation to form a brand-new image. Imagination is an important quality that must be possessed by choreographers. With its rich imagination, students can abstractly represent concrete objective things through dance movements and give new meaning to dance works.

In the process of implementing choreographers, choreographers must learn to use images and creative thinking to highly summarize the relevant materials that exist in life according to actual needs. In the process of creation, the dance image is closely related to the perceptual material existing in life. Therefore, dance creation should be driven by emotions to expand the author's imagination. Only with rich emotions as a solid back end, can choreographers lead his imagination to wings and fly.

\section{The Cultivation of Image Thinking in Choreography Teaching}

All art forms come from life and above life. Dances are the same. Vivid and vivid dance images are also based on the author's rich life experience. Dance works that do not have a basis for life are lacking vitality and empty body movements. For example, Zhang Jigang's works "To the Deaf Mother" and "The Love of the Yellow River" all come from the Loess Plateau in the northwest. This is because the author once lived in Shanxi for many years and has accumulated a lot of life perceptions and dance images. The unique dance image expresses her passion and attachment to the northwest region. The author presents the world with life through the dance works. In turn, the many years of northwestern life have also become the author's artistic creation.

Dance beginners mainly imitate the gestures of the teacher. Imitation can enhance students' tactile feelings and enrich their body language to improve the efficiency of dance learning. Compared with people's emotional color, not only can people be compared to a specific thing, but also can compare other things to adults. Whether it is a positive comparison or a reverse comparison, it can vividly depict emotional images of dance. When students are learning, they must carefully 
observe the surrounding scenes and objects, and develop their own image thinking ability through comparison and simulation. At the beginning, static objects can be imitated. For example, “Avalokitesvara" and "Flying Sky" are all mimicking the murals of Mogao Grottoes in Dunhuang; they can then imitate movement patterns, environment, etc., such as the gestures of certain animals and activities. Customary behavior, instinctive action, and so on. In the famous ballet "Swan's Death", Pavlovova imitated a dying white swan and called for life by gently shaking his arms, expressing his infinite yearning for life. In the end, I began to imitate the psychological characteristics of the imitation object, figure out the character of the dance image, the process of emotional development, etc. This requires that the choreographer has keen observation power and can accurately grasp the form, rhythm, rhythm, and emotion of the objective things.

In a sense, graphic arts such as shadow art, graphic design, and artistic artwork in fine art have many similarities with dance art. Both of them appreciate the works through visual senses. Vision is the most complex, subtle and sensitive feeling of human beings. It is also an important source for people to obtain a large amount of information. The combination of learning of dance choreography and graphic arts helps students to improve their thinking ability. Teachers should consciously ask students to watch graphic arts in order to obtain richer life materials. The graphic arts are rich in colors and smooth lines. Appreciating such works can give students greater visual impact. For example, the "Three Miles of Rivers and Mountains" that Korean women supported in the war during the War of Resistance Against Japan and U.S. Aid Korea was created by the oil painting and its own real experience. In the face of a strong visual impact, the author remembered The images of fighting with the North Koreans and fighting with each other are reflected in the minds of the mind and eventually created this stunning work. In addition, the teacher should also guide students to pay more attention to advertising images in daily life. Advertising in public places is both artistic and interesting. All these can be incorporated into the works as dance elements, and they are good for training students' image thinking. Reference function.

When cultivating the student's image thinking, the teacher should continuously enrich the content and form of choreography teaching and use different teaching methods for different types of dance. For example, for lyrical dance, it is necessary to consciously guide students to feel the spiritual connotation and ideological expression of each dance work. Because students have a short life experience, they must accumulate rich material through a lot of meticulous observations to understand and master the choreographer. The method and the connotation of dance works; guide students to integrate dance culture into their daily life, make them feel the close relationship between art and life, feel the beauty of art everywhere in daily life, and feel in art learning To life is the source of art, and gradually train students' image thinking. For the narrative dance choreographer, the teacher must consciously guide the students to take note of the different dance scenes, simplify the complex dance content through abstract expression as far as possible, and enable the students to better perceive the theme and emotion expressed in the dance work, and help them continuously Form image thinking.

\section{Conclusion}

In short, as an image art and performance art, dance has a higher requirement for the development of the image thinking of the choreographer. Choreographers must have a higher sense of perceptivity, stronger comprehension and thinking ability, rich imagination and cultural and artistic accomplishments. It is good at observing and perceiving the bits and pieces of life in order to accumulate richer creative material, thereby achieving a high degree of fusion of dance techniques, emotions, and forms of expression, and ultimately creating a classic art image that achieves a spiritual resonance with the audience. In the teaching process, the teacher should clearly coordinate the relationship between the image thinking and the abstract thinking, capture the lively and vivid dance image in life, cultivate the students' image thinking through various methods such as comparison, graphic image, and rich dance content form, and continuously improve the students' thinking. His comprehensive ability and artistic accomplishment will eventually create more artistically appealing works. 


\section{Acknowledgements}

Fund Project: Artistic Practice of Military and Civil Integration - Creation and Research of "Red Dance" in Colleges and Universities (17JMR12) Office of Military and Civil Integration of Shaanxi Province; Basic Skills Teaching and Research in Popular Dance Education (SGH16H203) Shaanxi Provincial Education Science Planning Leading Group Office

\section{References}

[1] LIU Ying, WANG Xiaoshuang. Analysis of the Advantages of Chinese National Dance Elements in Competitive Aerobics: Taking National Dance, Costume, and Music as Examples[J]. Journal of Anhui Normal University (Natural Science), 2014, 37(6) ): 601-604.

[2] Li Xiaoyan. Staring at the sky, staring at the sky_—From the dance practice "The South of the Fengqiling Mountains" to the Xinghai Conservatory of Music dance school ideas [J]. Xinghai Conservatory of Music Journal, 2013 (3): 157-161.

[3] Jing Zhiwei. Thinking and practice of the teaching theory of blending art theory with dance theory course_- Talking from the teaching of dance aesthetics in engineering colleges [J]. Journal of Beijing University of Aeronautics and Astronautics (Social Science Edition), 2014, 27 ( 6): 104-106.

[4] Hu Yi, He Liyang. Status Quo Analysis and Development of Dance Higher Education in Guangdong Province: A Case Study of the Dance Department of Xinghai Conservatory of Music [J]. 2013(6):122-125.

[5] Cui Shuang. On the cultivation of image thinking and imagination in choreographer [J]. Music Time, 2014, 07:55.

[6] Huang L. Talking about the Cultivation of Creativity in the Teaching of Dance Choreographer[J]. Journal of PLA University of Arts, 2010, 04:94-96. 